Portland State University

PDXScholar

Electrical and Computer Engineering Faculty

Publications and Presentations

$4-12-2017$

\title{
Electrodynamic Wheel Magnetic Rolling Resistance
}

Wei Qin

Beijing Jiaotong University

Jonathan Z. Bird

Portland State University, bird@pdx.edu

Follow this and additional works at: https://pdxscholar.library.pdx.edu/ece_fac

Part of the Electrical and Computer Engineering Commons

Let us know how access to this document benefits you.

\section{Citation Details}

Qin, Wei and Bird, Jonathan Z., "Electrodynamic Wheel Magnetic Rolling Resistance" (2017). Electrical and Computer Engineering Faculty Publications and Presentations. 418.

https://pdxscholar.library.pdx.edu/ece_fac/418

This Post-Print is brought to you for free and open access. It has been accepted for inclusion in Electrical and Computer Engineering Faculty Publications and Presentations by an authorized administrator of PDXScholar. Please contact us if we can make this document more accessible: pdxscholar@pdx.edu. 


\title{
Electrodynamic Wheel Magnetic Rolling Resistance
}

\author{
Wei Qin (秦伟), Member, IEEE, Jonathan Z. Bird, Member, IEEE \\ Portland State University, Department of Electrical and Computer Engineering, Portland, OR, USA
}

In this paper the concept of magnetic rolling resistance (MRR) is introduced. The MRR is particularly useful when trying to characterize maglev devices that operate with a slip. Approaches to minimize the MRR for an electrodynamic wheel magnetic suspension device are discussed. MRR is calculated from the power losses and it is shown that by using MRR a direct performance comparison with existing modes of transportation can be made. The MRR for a number of different maglev designs is calculated.

Index Terms - Analytical models, eddy currents, electromagnetic forces, Halbach rotor, magnetic levitation, magnetic losses

\section{INTRODUCTION}

$\mathrm{T}$ HE mechanical rolling resistance (RR) force is the force required to keep a wheel rolling. The mechanical RR force, $F_{d}$, is related to the normal force, $F_{y}$, on a wheel by [1]

$$
F_{d}\left(v_{x}\right)=\left(a+b v_{x}\right) F_{y},[\mathrm{~N}]
$$

where $v_{x}=$ translational velocity and the constant terms $a$ and $b$ are invariably determined experimentally [2]. The speed term in (1) is only used to model the mechanical losses in high-speed trains $[1,2]$. The ratio of RR force to normal force is called the rolling resistance coefficient and is defined as

$$
c\left(v_{x}\right)=\frac{F_{d}\left(v_{x}\right)}{F_{y}}
$$

for the Japanese Shinkansen series 200 high-speed train the RR coefficients are $a=0.0012$ and $b=15 \times 10^{-6} \mathrm{~s} / \mathrm{m}$ [1]. Therefore, at $360 \mathrm{~km} / \mathrm{h}$ the rolling resistance coefficient is only $c=0.0027$.

For electrodynamic suspension (EDS) devices the lift-todrag ratio

$$
L_{d}\left(v_{x}\right)=\frac{F_{y}\left(v_{x}\right)}{F_{x}\left(v_{x}\right)}
$$

is often used to characterize the devices suspension performance, where $F_{y}=$ lift force and $F_{x}=$ eddy current drag force. Equation (3) is just the inverse of (2). In suspension devices that operate with a slip speed, such as an electrodynamic wheel (EDW), the drag force, $F_{x}$, can be made to be zero or a positive thrust force [3,4]. For such devices (3) will not be a useful metric.

In this paper a magnetic rolling resistance (MRR) metric is proposed that allows a maglev vehicles' performance to be intuitively compared with traditional modes of transportation. The utility of the MRR is demonstrated by using it to study the performance limits of an EDW driven maglev vehicle $[3,5,6]$.

\section{Magnetic Rolling Resistance}

The electrodynamic drag force typically encountered in maglev vehicles can be converted into a thrust force if the magnetic source is rotated mechanically [3, 4], as illustrated in Fig. 1. The

Manuscript received Nov. 20, 2016. Date of publication June, 2017;. Corresponding authors: W. Qin (email: qinwei@pdx.edu), J. Z. Bird (e-mail: jonathan.bird@ieee.org).

Digital Object Identifier (inserted by IEEE).

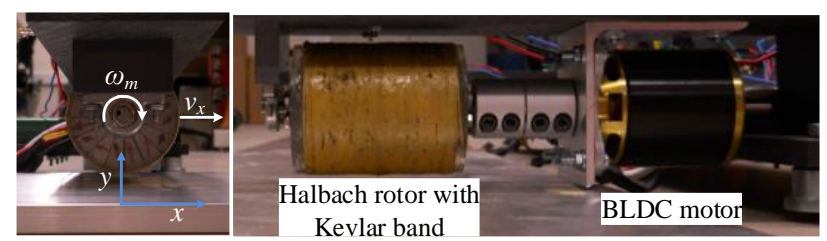

(a)

(b)

Fig. 1. (a) Side view and (b) front view of a sub-scale two pole-pair Halbach. The Halbach rotor is rotated at angular velocity, $\omega_{m}$, and translational move at velocity $v_{x}$ above the flat aluminum guideway.

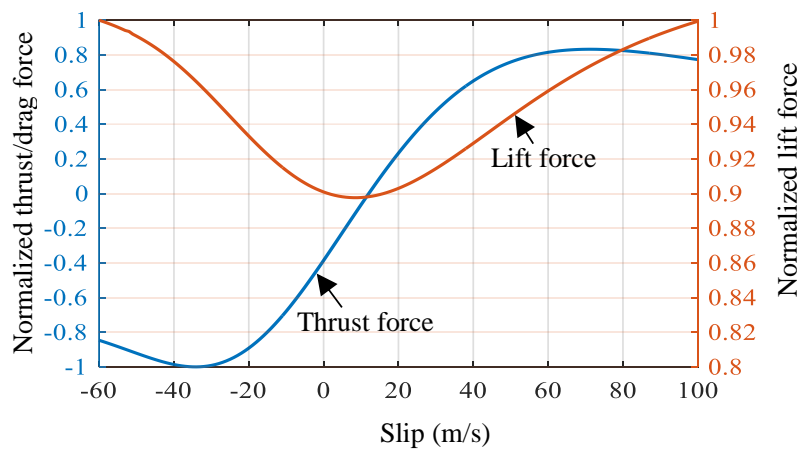

Fig. 2. Normalized lift and drag/thrust force for a single EDW moving with translational velocity $v_{x}=300 \mathrm{~km} / \mathrm{h}$

eddy current forces are dependent on a slip:

$$
s=\omega_{m} r_{o}-v_{x}
$$

where $\omega_{m}=$ mechanical angular velocity, $r_{o}=$ outer rotor radius.

The mechanical and electrical angular velocity are related by the number of pole-pairs, $p$. By adjusting slip, $s$, the force $F_{x}$ can be made to be zero. This is shown in Fig. 2. The lift-to-drag ratio given by (3) is then meaningless (since $F_{x}=0$ ). A more useful metric for measuring the lift performance, for slip dependent devices, is to use specific power:

$$
S_{p}\left(v_{x}\right)=\frac{P_{L}\left(v_{x}\right)}{F_{y}\left(v_{x}\right) / g} \quad[\mathrm{~W} / \mathrm{kg}]
$$

where $g=9.81 \mathrm{~ms}^{-2}$. The denominator is the mass. This metric is not normally used to measure performance in traditional transportation vehicles and therefore using (5) makes comparisons difficult. The drag force given in (2) can also be computed using the power loss and then one has

$$
c\left(v_{x}\right)=\frac{P_{L}\left(v_{x}\right)}{v_{x} F_{y}\left(v_{x}\right)}
$$


Equation (6) can also be used to characterize the magnetic suspension performance for electromagnetic slip dependent devices, where the power loss is then due to eddy current and hysteresis losses rather than mechanical frictional losses, the rolling resistance computed using (6) can then be thought of as being a MRR. As (6) is calculated using power loss it will never be zero, unlike with (2). An illustration of how the MRR and efficiency changes as a function of slip and pole-pairs, $p$, for a single EDW is shown in Fig. 3. Table 1 gives the parameters used to create Fig. 3. The forces were computed using the 3-D analytic model presented in [7,8]. The inner radius, $r_{i}$, of the Halbach rotor used in this, and in the following analysis, was selected so as to maximize the lift-to-weight ratio for the given pole-pair number [9]. Fig. 3(a) shows that the MRR improves (becomes lower) as the pole-pair number decreases; however, Fig. 3(b) shows that a lower pole number significantly reduces the thrust efficiency, $\eta$. The efficiency was calculated from

$$
\eta\left(v_{x}\right)=\frac{F_{x}\left(v_{x}\right) v_{x}}{F_{x}\left(v_{x}\right) v_{x}+P_{L}\left(v_{x}\right)}=\frac{F_{x}\left(v_{x}\right) v_{x}}{T\left(v_{x}\right) \omega_{m}}
$$

where $T\left(v_{x}\right)=$ torque and $F_{x}\left(v_{x}\right)=$ positive traction force. It should be noted that in this analysis the eddy current losses within the EDW magnets is neglected. If the magnets are not highly segmented this loss could be significant.

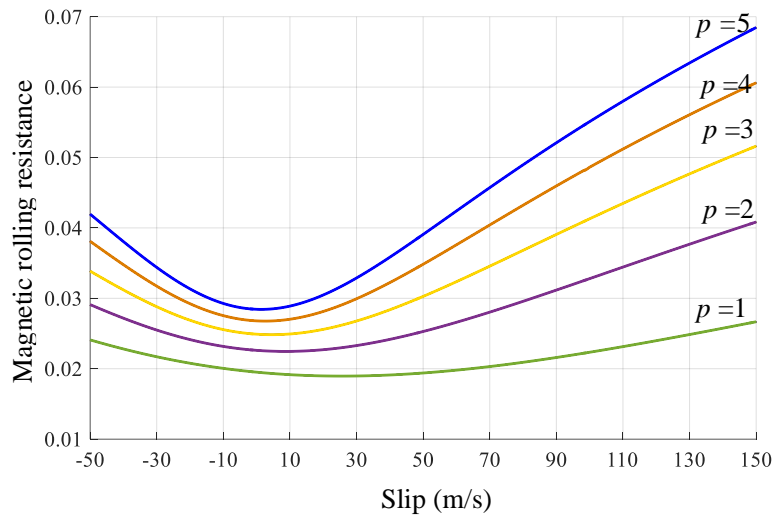

(a)

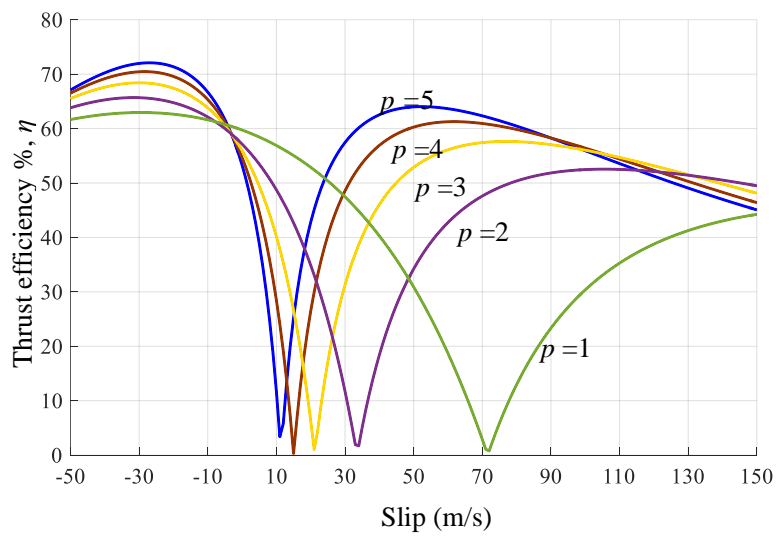

(b)

Fig. 3. (a) Magnetic rolling resistance, for one EDW and (b) the corresponding efficiency, $\eta$, as a function of slip for different number of pole-pairs when $v_{x}=360 \mathrm{~km} / \mathrm{h}(100 \mathrm{~m} / \mathrm{s})$. The geometric and material parameters shown in Table 1 were used. The power loss is only computed in the conductive plate. To create this figure the model presented in the $[7,8]$ was used.
A trade-off between minimizing MRR or maximize efficiency exists for the EDW. One means of achieving both a lower MRR and high efficiency, is to utilize multiple EDW in series [9], as illustrated in Fig. 4 and Fig. 5. In general, the MRR is lower when the number of pole-pairs, $p$, is lower, outer radius, $r_{o}$, is larger, track conductivity is higher and track thickness, $t$, is increased. The MRR decreases when the translational speed increases. This is opposite to the mechanical friction based RR relationship.

The EDW minimum MRR always occurs when the slip is controlled to make $F_{x}=0$. This is illustrated in Fig. 6 for the case when five EDWs in series are translationally moving at a velocity of $v_{x}=100 \mathrm{~m} / \mathrm{s}$ (with $p=2$ pole-pairs on each rotor). Fig. 6 also demonstrates that by both rotating and translationally moving the EDW a lower MRR can created than if it is only translationally moving. For instance, by looking at Fig. 6. one can see that if the slip is $s=-100 \mathrm{~m} / \mathrm{s}$ then from (4) $\omega_{m}=0$ and $v_{x}=100 \mathrm{~m} / \mathrm{s}$ and so in this case when there is only translational motion the MRR is not at a minimum. This indicates that the simultaneous rotation and translation of magnets lowers the MRR when compared to relying only on translational velocity for eddy current magnetic suspension.

Through parameter analysis it was determined that there are two important ratios that play a significant role in minimizing the MRR, they are the rotor width, $b$, to outer radii ratio defined as

$$
\Lambda=b / r_{o}
$$

and the rotor offset, $d$ to outer radii ratio defined as

$$
\Gamma=d / r_{o}
$$

The impact that these two ratios have on the MRR will be studied in the following two sections.

TABLE 1.

\begin{tabular}{l|lll}
\multirow{2}{*}{ SIMUlation PARAMETERS } \\
\cline { 2 - 4 } & Description & Value & Unit \\
\hline \multirow{4}{*}{ Rotor } & Outer radius, $r_{o}$ & 0.4 & $\mathrm{~m}$ \\
& Inner radius, $r_{i}$ & $r_{i}(p)^{*}$ & $\mathrm{M}$ \\
& Magnet $(\mathrm{NdFeB}), B_{r}$ & 1.42 & $\mathrm{~T}$ \\
& Rotor offset, $d$ & 0.2 & $\mathrm{M}$ \\
& Airgap, $g$ & 10 & $\mathrm{~mm}$ \\
& Width, $b$ & 0.4 & $\mathrm{M}$ \\
\hline \multirow{2}{*}{ Conductive late } & Conductivity, $\sigma(\mathrm{Cu})$ & $5.69 \times 10^{7}$ & $\mathrm{Sm}^{-1}$ \\
& Thickness, $t$ & 50 & $\mathrm{~mm}^{\circ}$ \\
\hline \hline
\end{tabular}

* where: $r_{i}(1)=0, r_{i}(2)=0.37 r_{o}, r_{i}(3)=0.575 r_{o}, r_{i}(4)=0.684 r_{o}, r_{i}(5)=0.746 r_{o}$.

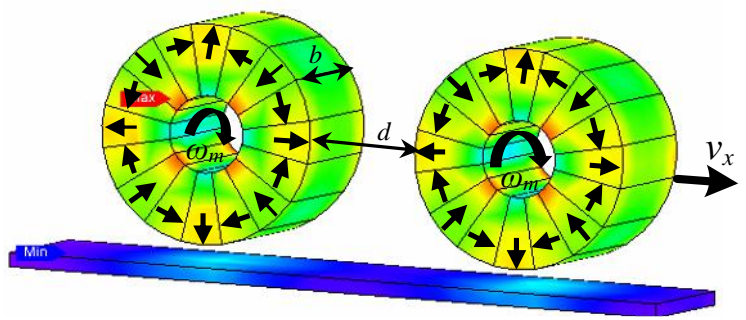

Fig. 4. Two electrodynamic wheels in series, with rotor offset $d$, axial rotor width $b$, rotor angular velocity, $\omega_{m}$ and translational velocity, $v_{x}$. 


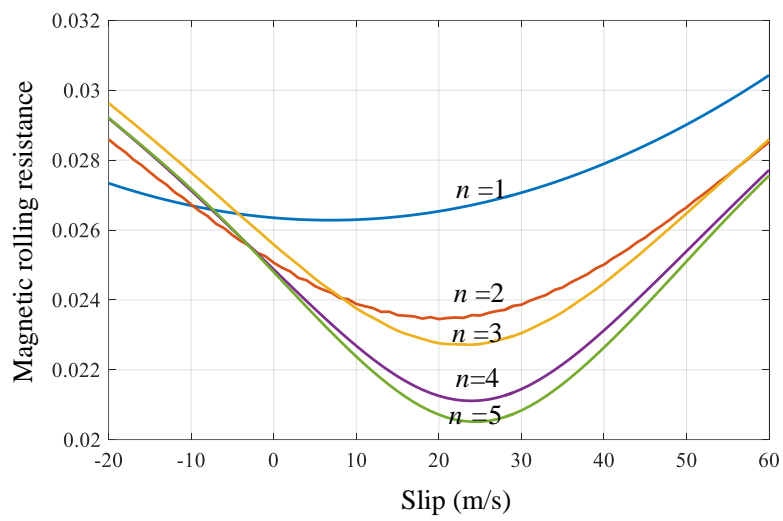

Fig. 5. Magnetic rolling resistance as a function of slip for $n$ EDWs in series when $v_{x}=100 \mathrm{~m} / \mathrm{s}$. In this plot each EDW has 2 pole-pairs with rotor offset $d=0.2 \mathrm{~m}$, outer radii $r_{o}=0.4 \mathrm{~m}$ and rotor width $b=0.4 \mathrm{~m} .(\Gamma, \Lambda)=(0.5,1)$. The 3-D equations used to compute the results in this figure are given in the Appendix.

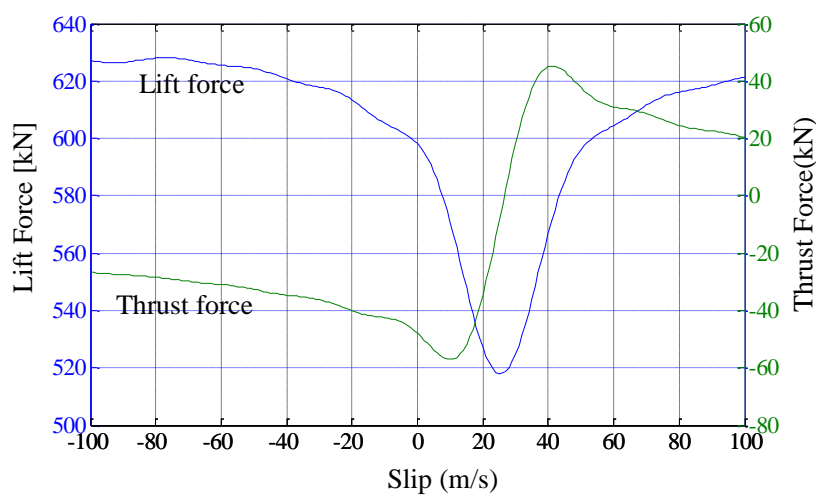

(a)

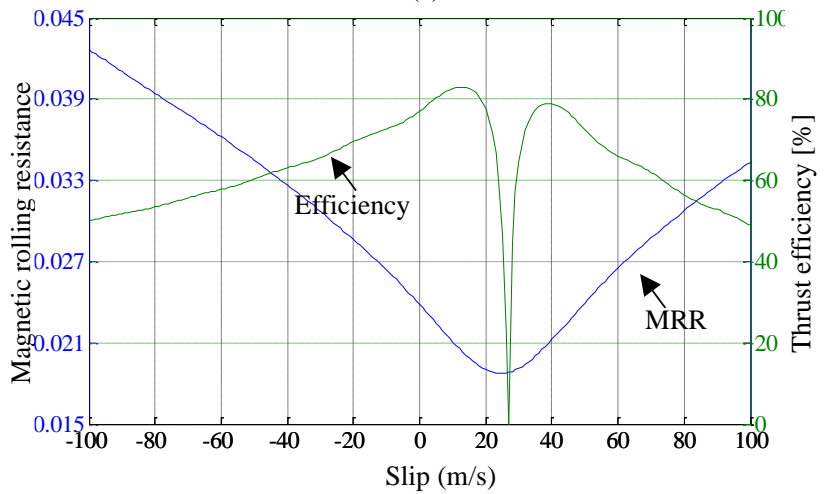

(b)

Fig. 6 (a) The thrust, suspension and (b) efficiency, magnetic rolling resistance as a function of slip speed when $v_{x}=360 \mathrm{~km} / \mathrm{h}(100 \mathrm{~m} / \mathrm{s})$. Results are for $n=5$ rotors in series with $p=2$ pole-pair with an outer radius of $r_{o}=0.4 \mathrm{~m}$. $(\Gamma, \Lambda)=(0.5,1.6)$.

\section{A. Rotor Width to Outer Radius Ratio}

Consider the case in which the number of EDWs in series and pole-pairs is kept at $(n, p)=(5,2)$, and the speeds are $\left(v_{x}, s\right)=(100,20) \mathrm{m} / \mathrm{s}$ and $\Gamma=0.6$. Then if the MRR is computed for different outer radii and rotor width values the plot shown in Fig. 7 can be obtained. It can be seen in this plot that the MRR decreases as the rotor width, $b$, increase but with a diminishing return. The decreasing improvement in MRR is more clearly seen in Fig. 8. As the rotor width is increased the 3-D edge fringing effects play a smaller role in changing the performance when compared to a 2-D model. The point at which the MRR reduces to $95 \%$ of its minimum value is marked with a black dot. In this example case this occurs at $\Lambda=1.6$. This $\Lambda$ value does not change with numbers of EDWs as shown in Fig. 9 however the $\Lambda$ value that gives the lowest MRR does change with pole-pair number as shown in Fig. 10. In the next section $(n, p)=(5,2)$ with $\Lambda=1.6$ will be used as this a practical ratio and also gives one of the lowest MRR values.

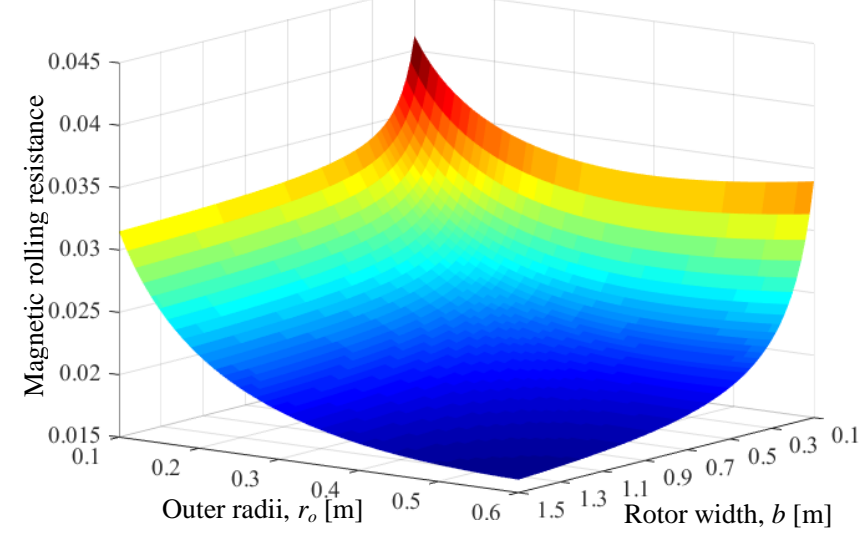

Fig. 7 Magnetic rolling resistance as a function of outer rotor radii and rotor width for $n=5$ EDWs in series that have 2 pole-pair each when $v_{x}=100 \mathrm{~m} / \mathrm{s}$, $s=20 \mathrm{~m} / \mathrm{s}$ and $\Gamma=d / r_{o}=0.6$.

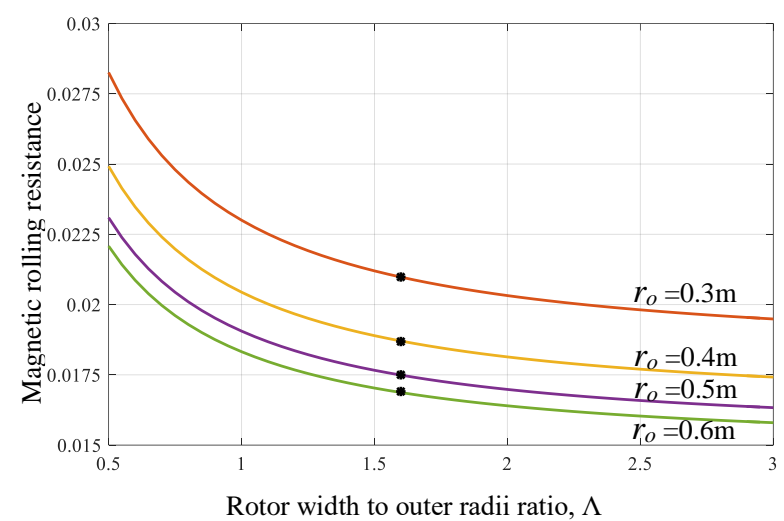

Fig. 8 Magnetic rolling resistance as a function of outer rotor radius to width ratio, $\Lambda$, for $(n, p, \Gamma)=(5,2,0.6)$ and $\left(v_{x}, s\right)=(100,20)$, Note that the point $\bullet$ on the figure denotes the ratio $\Lambda=1.6$ at which $95 \%$ of the minimum MRR was reached.

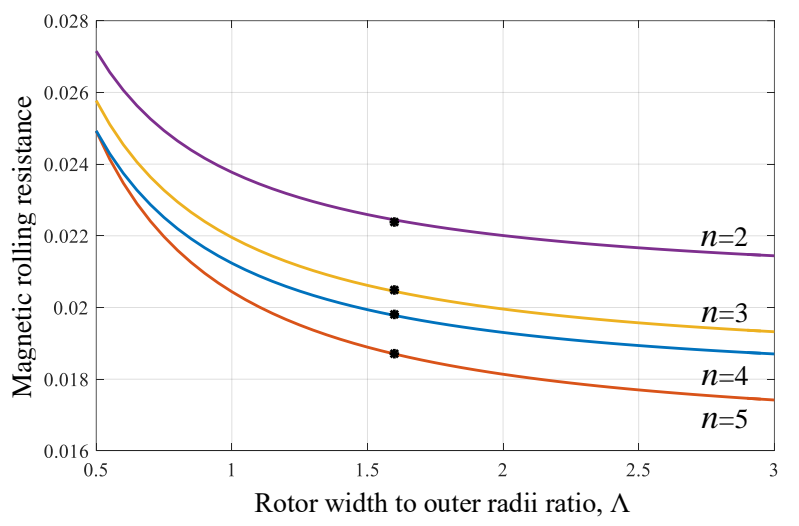

Fig. 9 Magnetic rolling resistance as a function of rotor width to outer radii for different number of EDW when $p=2,\left(r_{0}, d\right)=(0.4,0.24), \Gamma=0.6$ and $\left(v_{x}, s\right)=$ $(100,20)$. The point at which MRR reaches $95 \%$ of its minimum value is marked with a black dot, this point does not change when the number of EDWs in series changes. 


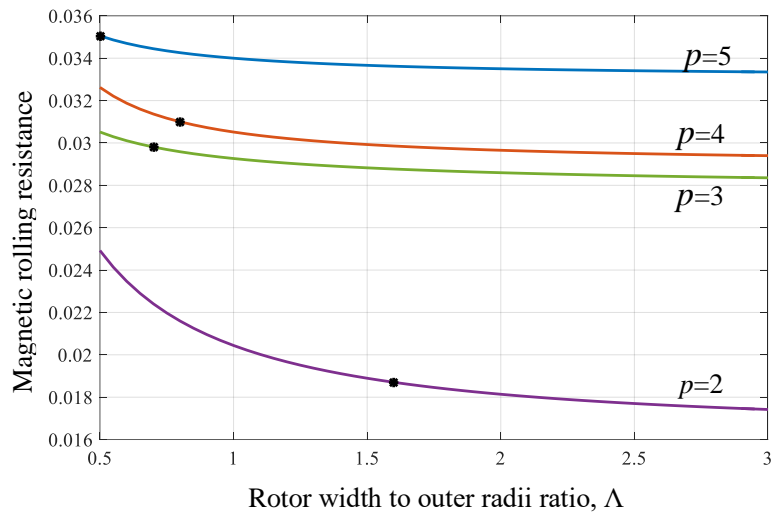

Fig. 10 Magnetic rolling resistance as a function of rotor width to outer radii ratio, $\Lambda$, for different number of pole-pairs when $n=5 \mathrm{EDWs}$ are in series. $\Gamma=0.6$ and $\left(v_{x}, s\right)=(100,20)$. $)$. The point at which the MRR reaches $95 \%$ of its minimum value is marked with a black dot.

\section{B. Rotor Offset to Outer Radii Ratio}

As the MRR is always a minimum when $F_{x}=0$ this condition can be used to investigate how the MRR changes when the $\Gamma$ - ratio changes. As an example, consider the case shown in Fig. 11 in which the rotor offset, $d$ and outer radii, $r_{\mathrm{o}}$ were both varied and $(n, p, \Lambda)=(5,2,1.6)$ and $\left(v_{x}, s\right)=(100,20) \mathrm{m} / \mathrm{s}$ were kept constant. At this operating point the MRR is always at a minimum when $\Gamma=0.59$. This ratio condition is shown as a black line in Fig. 11 for different $r_{o}$ values. However, the selected slip value of $s=20 \mathrm{~m} / \mathrm{s}$ used to create Fig. 11 does not give the lowest MRR value since at this slip value $F_{x} \neq 0$ (as one can note by examining the slip value that gives the minimum MRR in Fig. 6). Therefore, at each translational velocity, $v_{x}$ there is a slip value, $s$ at which $F_{x}=0$ and by plotting the MRR value at the $F_{x}=0$ condition for different translational velocities and $\Gamma$ ratios a plot such as shown in Fig. 12 can be created. Fig. 12 shows the minimum MRR value at each $\Gamma$ ratio for four different translational velocities. What is interesting to note is that the $\Gamma$ ratio is always $\Gamma=0.2$. Therefore, one can conclude that for the $(n, p)=(5,2)$ combination $\Gamma=0.2$ will always result in the lowest MRR design. A similar analysis for different numbers of pole-pairs can be conducted. This results is shown in Fig. 14 for the case when $v_{x}=100 \mathrm{~m} / \mathrm{s}$, it can be seen that using 2 pole pairs results in the lowest MRR value. Higher numbers of polepairs increase the minimum MRR since the electrical frequency will increase. When using $p=4$ and $p=5$ pole-pairs the minimum MRR occurs when $\Gamma=0$. This would not be a feasible design point as this would mean that the rotors would touch. The increase in number of EDWs in series does not change where the optimal $\Gamma$-value is located. This is illustrated in Fig. 14 for the case when $\left(p, \Lambda, \Gamma, r_{o}\right)=(2,0.2,1.6,0.4)$. Fig 14 also shows that as $n$ increases the MRR decreases. However, this improvement does not continue indefinitely as illustrated in Fig. 15. The lowest MRR for the 2 pole-pair EDW when $r_{o}=0.4 \mathrm{~m}$ is shown to be $c=0.0165$ when operating at $v_{x}=100 \mathrm{~m} / \mathrm{s}(360 \mathrm{~km} / \mathrm{h})$. This indicates that the use of electrodynamic magnetic suspension will increase the rolling resistance by a factor of 6 relative to the rolling resistance of a Japanese Shinkansen 200 high-speed train travelling at the same $360 \mathrm{~km} / \mathrm{h}$ speed.

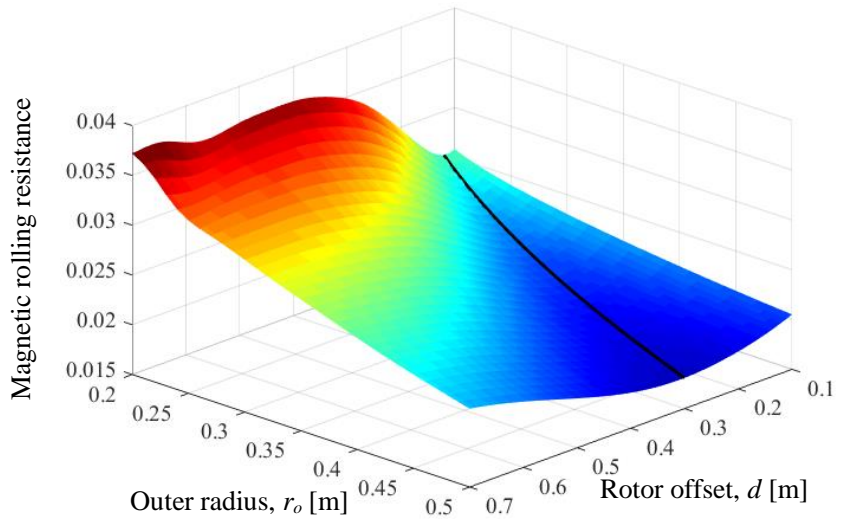

Fig. 11 Magnetic rolling resistance as a function of rotor radius and rotor offset $d$ for five EDWs in series that have 2 pole-pair each at $v_{x}=100 \mathrm{~m} / \mathrm{s}$, $s=20 \mathrm{~m} / \mathrm{s}$.

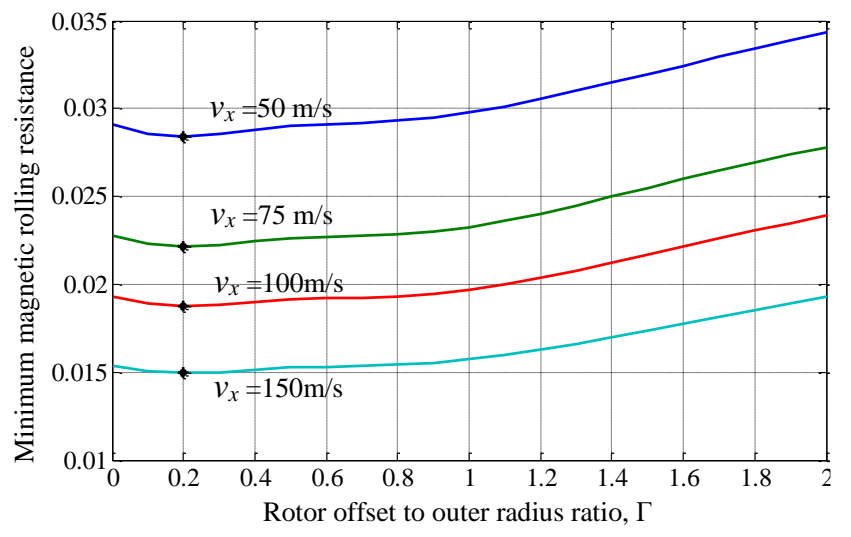

Fig. 12 Minimum magnetic rolling resistance as a function of rotor offset to radius ratio, $\Gamma$, for $(n, p, \Lambda)=(5,2,1.6)$ and $r_{0}=0.4 \mathrm{~m}$. when $v_{x}=50,75,100$ and $150 \mathrm{~m} / \mathrm{s}$.

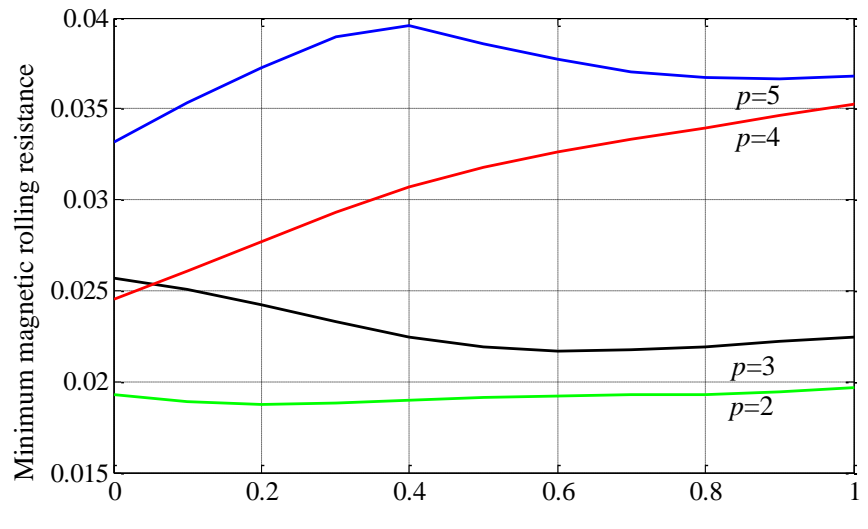

Rotor offset to outer radius ratio, $\Gamma$

Fig. 13 Magnetic rolling resistance as a function of pole-pairs in series when $v_{x}=100 \mathrm{~m} / \mathrm{s}$ and $\left(n, \Lambda, r_{o}\right)=(5,0.2,0.4)$ 


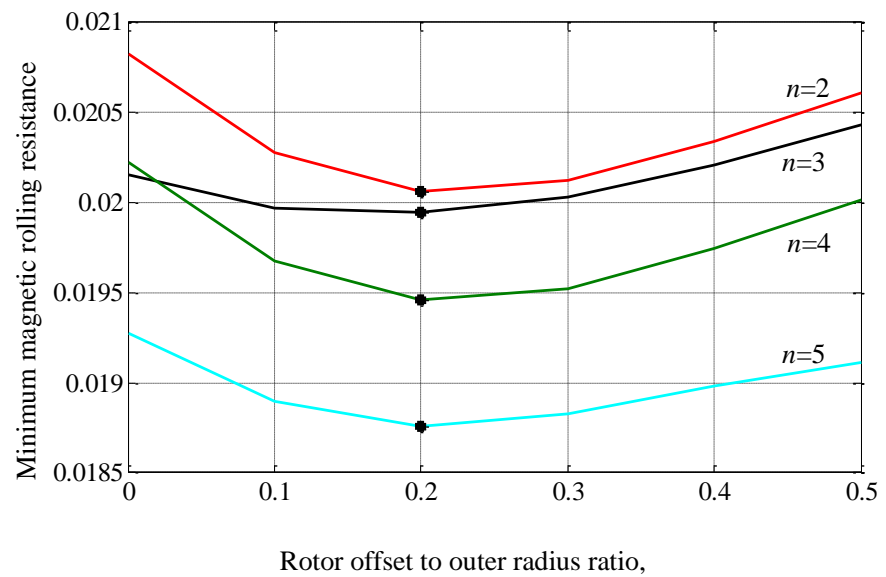

Fig. 14 Magnetic rolling resistance as a function of numbers of EDW in series when $v_{x}=100 \mathrm{~m} / \mathrm{s},(p, \Lambda)=(2,1.6), r_{\mathrm{o}}=0.4 \mathrm{~m}$. It can be noted that the optimal rotor offset to outer radii ratio, $\Gamma$ does not change with number of EDS.

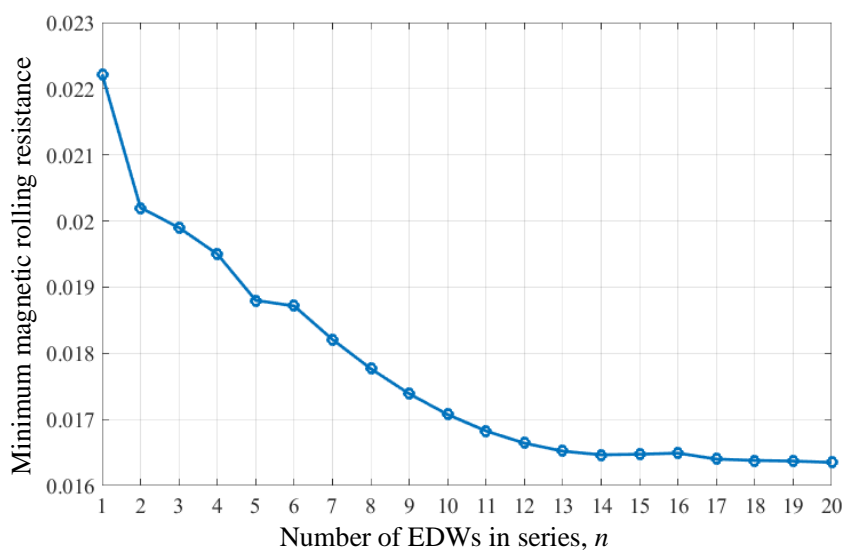

Fig. 15 Magnetic rolling resistance as a function of numbers of EDW in series when $v_{x}=100 \mathrm{~m} / \mathrm{s}$ and $\left(p, \Lambda, \Gamma, r_{o}\right)=(2,0.2,1.6,0.4)$.

\section{PERFORMANCE COMPARISON}

A comparison of a number of different MRR values for proposed and operational maglev systems is shown in Table 2. It can be noted that none appear to be competitive with the RR of a high-speed train. The EML system can have a low MRR because the guideway is made up of laminated steel. Laminated steel was shown to be necessary when operating above $100 \mathrm{~km} / \mathrm{h} \mathrm{[10]}$. The use laminated steel results in an extremely costly guideway structure.

TABLE 2.

MAGNETIC ROLLING RESISTANCE COMPARISON

\begin{tabular}{lllll}
\hline \hline Maglev design & Type & $\begin{array}{l}\text { Drag force } \\
(\mathrm{kN})\end{array}$ & $\begin{array}{l}\text { Velocity } \\
(\mathrm{km} / \mathrm{h})\end{array}$ & MRR \\
\hline Transrapid, TR07 [11] & EML* & 13.56 & 400 & 0.006 \\
G.A. Urban Maglev [12] & EDS & 1000 & 72 & 0.11 \\
Magplane [13] & EDS & - & 540 & 0.025 \\
HSST [14] & EML & 0.046 & 15 & 0.013 \\
\hline \multicolumn{4}{l}{}
\end{tabular}

* EML $=$ Electromagnetic levitation

\section{CONCLUSION}

This paper introduced the concept of MRR and it was used to study the performance of an EDW. Geometric design parameters were identified that can minimize the MRR for an EDW. It was shown that it is very difficult for a maglev vehicle to achieve the comparable operating RR values of a high-speed train. As an EDW has both rotational and translational motion the MRR can be minimized and therefore an EDW appears to offer the lowest MRR value of an EDS type maglev system.

\section{ACKNOWLEDGEMENT}

This research was supported and funded by the Fundamental Research Funds for the Central Universities of China (2015JBM0083) and China Postdoctoral Science Foundation (2014M550603).

\section{APPENDIX}

The second order magnetic vector potential steady-state eddy current model developed by Paul $[7,8]$ was modified to enable the EDW forces for multiple EDWs in series to be computed in 3 -D. The model presented in [7, 8] assumed that the conductive plate guideway is homogenous, simply connected, has infinite width (along the $x-z$ axis) and is composed of non-magnetic material $\left(\mu_{r}=1\right)$. The steady-state $F_{x}$ and $F_{y}$ eddy-current forces created by the rotation and translational motion of an EDW can be computed from $[7,8]$

$$
\mathbf{F}=w_{t} l_{t} \operatorname{Re}\left\{\sum_{m=-\infty}^{\infty} \sum_{q=-\infty}^{\infty} B_{m q}^{s n} R_{m q}\left[j \frac{\xi_{m}}{\kappa_{m q}} \hat{x}-\hat{y}\right]\right\}
$$

where $w_{t}$ is width of the track, $l_{t}$ is length of the conductive plate track and $R_{m q}$ is the reflection coefficient given by

$$
\begin{gathered}
R_{m q}=\frac{\mu_{0} \sigma \tau_{m q}}{\kappa_{m q}^{2}+\gamma_{m q}^{2}+2 \kappa_{m q} \beta_{m q} \operatorname{coth}\left(\beta_{m q} h\right)} \\
\kappa_{m q}^{2}=\xi_{m}^{2}+k_{q}^{2} \\
\xi_{m}=2 \pi m / l_{t} \\
k_{q}=2 \pi q / w_{t} \\
\beta_{m q}^{2}=\lambda^{2}+\gamma_{m q}^{2} \\
\lambda=-0.5 v_{y} \mu_{0} \sigma \\
\gamma_{m q}^{2}=\kappa_{m q}^{2}-j \mu_{0} \sigma\left(P w_{m}+\xi_{m} v_{x}+k_{q} v_{z}\right) \\
\tau_{m q}=\kappa_{m q} v_{y}+j\left(P w_{m}+\xi_{m} v_{x}+k_{q} v_{z}\right)
\end{gathered}
$$

The $B_{m q}^{s n}$ source field for $n=1 \mathrm{EDW}$ is given by

$$
B_{m q}^{s 1}=\frac{1}{\mu_{0}}\left|S_{m q}\right|^{2} e^{-2 \kappa_{m q} g}
$$

where $S_{m q}$ is computed from [7, 8]

$$
S_{m q}=\frac{1}{l_{t} w_{t}} \int_{-w_{t} / 2}^{w_{t} / 2} \int_{-l_{t} / 2}^{l_{t} / 2} B_{y}^{s o}(x, g, z, t) e^{-j \xi_{m} x} e^{-j k_{q} z} d x d z .
$$

The 3-D Halbach rotor source equation within the integral of (20) is defined in $[7,8]$. The track width $w_{t}$ and length $l_{t}$ must be selected to be sufficiently long so as to prevent any edge effects from corrupting the results.

When there are multiple EDW in series the field contribution from each of the EDWs in series must be summed up. For example, for $n=3$ EDWs in series the total field source equation becomes

$$
B_{m q}^{s 3}=B_{m q}^{s 1} e^{-j \xi_{m} 3 x_{o}}\left(e^{j \xi_{m} 1 x_{o}}+e^{j \xi_{m} 2 x_{o}}+e^{j \xi_{m} 3 x_{o}}\right)
$$


where

$$
x_{o}=2 r_{o}+d
$$

and for $n=N$ EDW in series the source field will be:

$$
B_{m q}^{s N}=B_{m q}^{s 1} e^{-j \xi_{m} N x_{o}} \sum_{h=1}^{N} e^{j \xi_{m} h x_{o}}
$$

The eddy current power loss in the conductive track due to $N$ EDWs in series can be computed from $[7,8]$

$$
P_{\text {loss }}=-w l \operatorname{Re}\left\{\sum_{m=-\infty}^{\infty} \sum_{q=-\infty}^{\infty} B_{m q}^{s n} \frac{R_{m q}}{\kappa_{m q}}\left(j \omega_{e}+j \xi_{m} v_{x}\right)\right\}
$$

The force and power loss equations given by (10) and (24) where verified by comparing the computed results with the force and power computed using a COMSOL finite element analysis (FEA) model. The comparison is shown in Fig. 16 and Fig. 17. The error comparison is shown in Fig 18. A good agreement was achieved.

TABLE 3. SimUlation PARAMETERS

\begin{tabular}{lll}
\hline \hline Description & Value & Unit \\
\hline Outer Halbach radius, $r_{o}$ & 0.05 & $\mathrm{~m}$ \\
Inner Halbach radius, $r_{i}$ & $0.37 r_{o}$ & $\mathrm{~m}$ \\
Wheels offset, $d$ & 0.05 & $\mathrm{~m}$ \\
Pole pair, $p$ & 2 & - \\
Rotor number, $n$ & 5 & - \\
Magnet residual flux density (Nd-Fe-B), $B_{r}$ & 1.42 & $\mathrm{~T}$ \\
Track conductivity, $\sigma$ & $5.69 \times 10^{7}$ & $\mathrm{Sm}^{-1}$ \\
Slip speed, $s$ & -30 to 30 & $\mathrm{~m} / \mathrm{s}$ \\
Track thickness, $t$ & 10 & $\mathrm{~mm}$ \\
\hline \hline
\end{tabular}

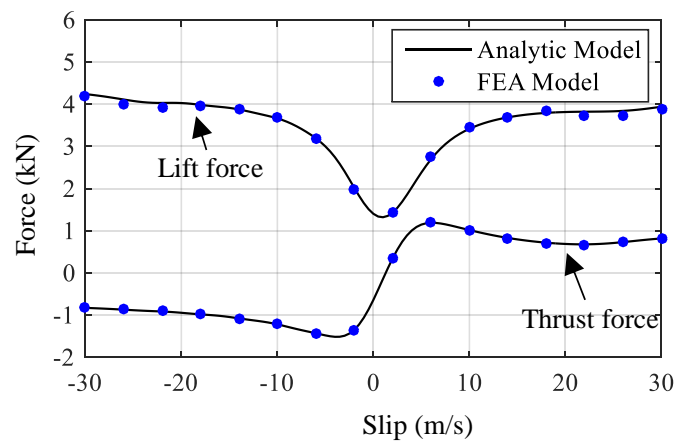

Fig. 16 Forces comparison between FEA and the analytic model with chang-

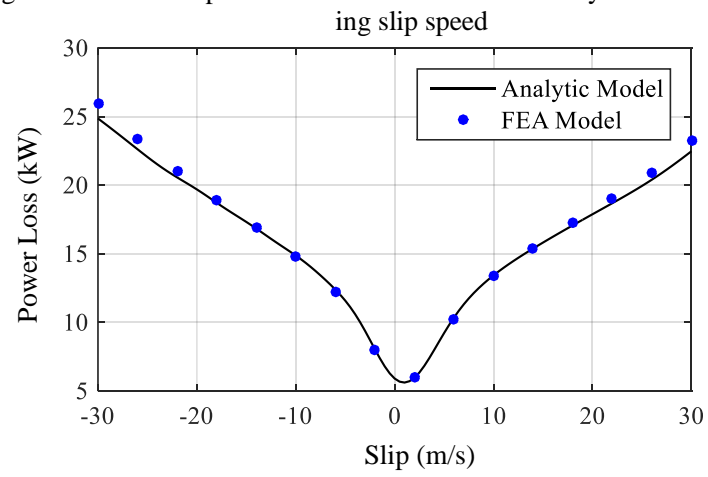

Fig. 17 Power losses comparison between FEA and the analytic model with changing slip speed

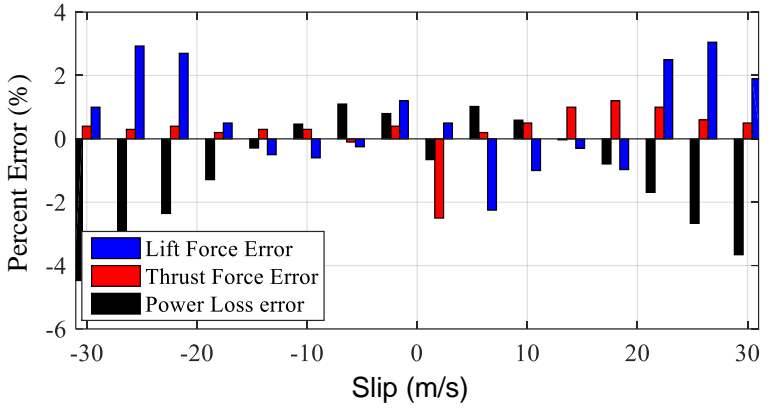

Fig. 18 Percentage error between FEA and Analytic model with changing slip speed

\section{A. Field and Current Exit Effects}

Using the parameters given in Table 3, the $y$-component of the source field at the surface of the track $(y=0)$ for $n=5 \mathrm{EDW}$ was plotted. The result is shown in Fig. 19. The EDWs were centered at $x=0 \mathrm{~m}$. The $B_{y}$ magnetic flux density and current density, $J_{z}$, in the longitudinal direction within the conducting track at a velocity and slip value $\left(v_{x}, s\right)=(25,20) \mathrm{ms}^{-1}$ is illustrated in Fig. 20 and Fig. 21 respectively. The oscillatory trailing nature of the induced eddy currents and field due to the motion of the EDWs is clearly evident. By using additional EDWs this trailing field can be used to boost the efficiency and lower the MRR of an EDW maglev system.

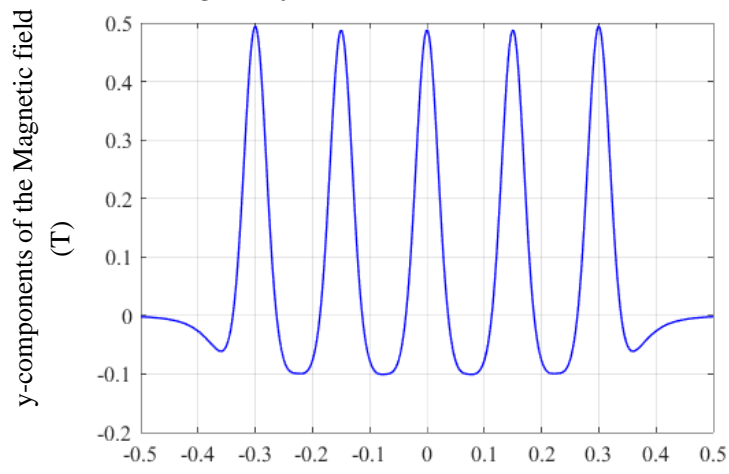

Fig. $19 y$-components of the source field at the upper surface of the track.

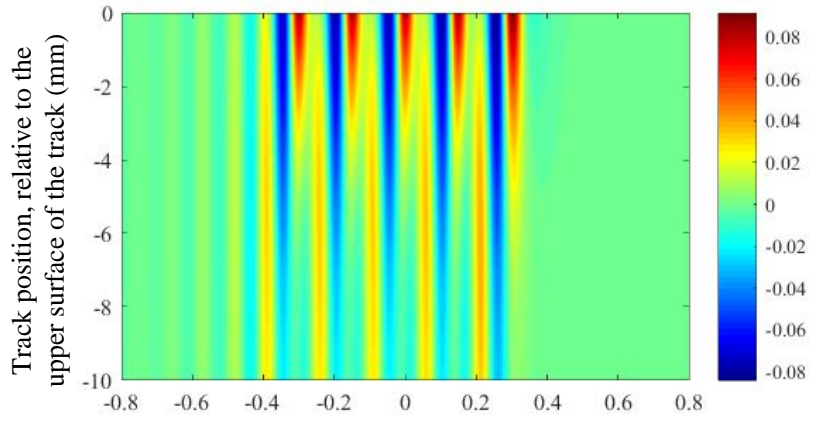

Fig. $20 y$-component of the magnetic flux density [T] within track with a translational velocity $v_{x}=25 \mathrm{~ms}^{-1}$ and a slip speed of $s=20 \mathrm{~ms}^{-1}$. 


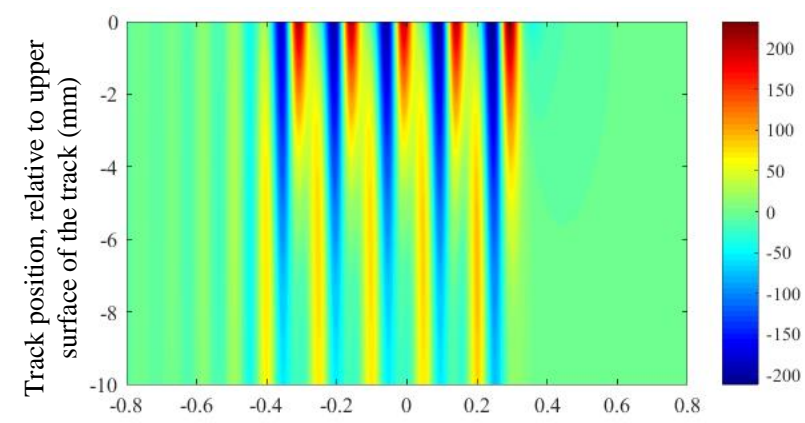

Fig. 21 Current density, $J_{z}\left[\mathrm{~A} / \mathrm{mm}^{-2}\right]$ within track with a $25 \mathrm{~ms}^{-1}$ translational velocity and a $20 \mathrm{~ms}^{-1}$ slip.

\section{REFERENCES}

[1] B. P. Rochard and F. Schmid, "A review of methods to measure and calculate train resistance," Proc. Instn. Mech. Engrs. Part F, vol. 214, no. 4, pp. 185-199, July 2000.

[2] P. Lukaszewicz, "Energy Consumption and Running Time for Trains," Ph.D., Dept. of Vehicle Eng., Royal Institute of Technology, Stockholm, 2001.

[3] S. Paul, W. Bomela, N. Paudel, and J. Z. Bird, "3-D Eddy Current Torque Modeling," IEEE Trans. Mag., vol. 50, no. 2, pp. 905-908, 2014.

[4] N. Fujii, M. Chida, and K. Ogawa, "Three dimensional force of magnet wheel with revolving permanent magnets," IEEE Transactions on Magnetics, vol. 33, no. 5, pp. 4221-4223, 1997.

[5] N. Paudel and J. Z. Bird, "Modeling the dynamic electromechanical suspension behavior of an electrodynamic eddy current maglev device," Progress in Electromagnetic Research B, vol. 49, no. pp. 1-30, 2013.

[6] N. Paudel, S. Paul, and J. Bird, "Dynamic Electromechanical Eddy Current Force Modeling," COMPEL: Intern. Jour. Comp. Math. Elect. Elec. Eng., vol. 33 no. 6, pp. 2101 - 2120, 2014.

[7] S. Paul, J. Wright, and J. Z. Bird, "3-D Steady-State Eddy-Current Damping and Stiffness Terms for a Finite Thickness Conductive Plate," IEEE Trans Magn., vol. 50, no. 11, pp. 1-4, 2014.

[8] S. Paul, "Three-dimensional steady state and transient eddy current modeling," Ph.D. Thesis, Elect. Comp. Eng., Univ. N.C. at Charlotte, Charlotte,NC, 2014.

[9] J. Bird and T. A. Lipo, "Characteristics of an electrodynamic wheel using a 2-D steady-state model," IEEE Trans. Magn., vol. 43, no. pp. 3395-3405, Aug. 2007.

[10] H. Ohsaki and J. Du, "Influence of eddy current induced in steel rails on electromagnetic force characteristics of EMS maglev systems," in 18th International Conference on Magnetically Levitated Systems and Linear Drives, Shanghai, China, 2004, pp. 960-965.

[11] T. Hopkins, J. Silva, B. Mader, B. Turman, and B. Kelly, "Maglift Monorail," presented at the High Speed Ground Trans. Ass., Seattle, WA, 1999.

[12] "Proceedings of the Federal Transit Administration's Urban Maglev Workshop," pp 82, Federal Transit Administration, Washington DC, Sept. 8-9 2005.

[13] R. Thome and A. Radovinsky, "EDS levitation and guidance using sheet guide ways," presented at the Maglev 2000 Conference, Rio de Janeiro, Brazil, 2000.

[14] J. Du and H. Ohsaki, "Numerical analysis of eddy current in the EMSMaglev system," in Sixth Inter. Conf. Elect. Mach. Sys., 2003, pp. 761764 vol.2. 